\section{Unintended Pregnancies and Failure to Prevent Them: Pakistan's Dilemma}

Sir,

Pakistan is experiencing a high birth rate which has been contributing to the health burden of the country. A Demographic and Health Survey, conducted in 2012-13, outlines that Pakistan is now the sixth most populous country in the world and is expected to become the fifth most populous by 2050 . This rapid population surge will hinder the country's economic growth and drain its dwindling resources. ${ }^{1}$

A major reason for this high birth rate is unintended pregnancies, the prevalence of which was reported to be $38.2 \%$, according to a study conducted using the London Measure of Unplanned Pregnancies (LMUP) in 2015,2 which is considerably higher than the $24 \%$ recorded by PDHS in 2013. ${ }^{1}$ A lack of contraceptive use was found to be the leading cause of this trend.2

There are persistent problems with access to and being able to afford to visit family planning centres or doctors, as well as a general lack of awareness and a fear of potential side effects. Furthermore, contraceptive use in Pakistan also remains low due to several social barriers. These include social stigma, religious beliefs and opposition from the husband as well as relatives that pressure women into avoiding proper family planning. ${ }^{3}$

There is an urgent need for a better system to spread awareness and improve accessibility amongst the populace, especially those living in rural areas. One such attempt was a research initiative conducted by the Marie Stopes Society to assess the comparative effectiveness of two family planning models. The Suraj and CMW models increased family planning awareness by $14 \%$ and $28 \%$, respectively, indicating the need of funded family planning facilities to a receptive population. ${ }^{4}$ A National Program for Family Planning and Primary Healthcare was initiated in 1994; however, according to a SWOT analysis conducted in 2013, it has been struggling to make an impact. This has been attributed to mismanagement at local levels, delays in paying salaries to the workers, job insecurity and overworking of workers, all of which have led to poor progress. Moreover, the program is further at jeopardy due to lack of financial support from the government, political interference and targeted killing of the workers as well as a patriarchal mindset established in social norms. 5

Hence, there is a need for a community based approach to this dilemma. Women should be educated so that they realise their biological rights. Encouraging women more towards college education would consequently decrease early marriages. Lady Health Workers should be provided with a safe working environment. A community-wide public awareness campaign, targeting young adults of both genders, should be instated, with special attention given to male awareness. Each individual should receive a tailor-made birth control strategy so that they feel more in control of the process. Intervention by religious leaders should be encouraged so that people involved are at ease with the idea of contraceptive use.

\section{REFERENCES}

1. Demographic P. Health Survey 2012-13. Islamabad: National Institute of Population Studies (NIPS) and Macro International Inc. 2013.

2. Habib MA, Raynes-Greenow C, Nausheen S, Soofi SB, Sajid M, Bhutta ZA, et al. Prevalence and determinants of unintended pregnancies amongst women attending antenatal clinics in Pakistan. BMC Pregnancy Childbirth 2017; 17:156.

3. Mustafa G, Azmat SK, Hameed W, Ali S, Ishaque M, Hussain W, et al. Family planning knowledge, attitudes, and practices among married men and women in rural areas of Pakistan: Findings from a qualitative need assessment study. Int $J$ Reproduct Med 2015; 2015:190520.

4. Azmat SK, Hameed W, Hamza HB, Mustafa G, Ishaque M, Abbas G, et al. Engaging with community-based public and private mid-level providers for promoting the use of modern contraceptive methods in rural Pakistan: results from two innovative birth spacing interventions. Reproduct Health 2016; 13:25.

5. Wazir MS, Shaikh BT, Ahmed A. National program for family planning and primary healthcare Pakistan: a SWOT analysis. Reproduct Health 2013; 10:60.

Sana Habib², Fatima Khan ${ }^{2}$ and Sara Habib ${ }^{1}$

1 Department of Neurosurgery and Neurocritical Care, Thomas Jefferson University, PA, USA

2 Medical Student, Dow University of Health Science, Karachi, Pakistan

Correspondence: Dr. Sara Habib, Department of Neurosurgery and Neurocritical Care, Thomas Jefferson University, 901 Walnut Street, Suite 332, PA, USA

E-mail: sara.habib@jefferson.edu

Received: June 25, 2018; Accepted: September 09, 2018 